\title{
Análise de isótopos de carbono e nitrogênio: a dieta antes e após a presença de cerâmica no sítio Forte Marechal Luz
}

\author{
Murilo Q. R. Bastos (*) \\ Andrea Lessa $\left({ }^{*}\right)$ \\ Claudia Rodrigues-Carvalho ${ }^{*}$ ) \\ Robert H. Tykot $\left.{ }^{* *}\right)$ \\ Roberto V. Santos (***)
}

\begin{abstract}
BASTOS, M.Q.R.; LESSA, A.; RODRIGUES-CARVALHO, C.; TYKOT, R.H.; SANTOS, R.V. Análise de isótopos de carbono e nitrogênio: a dieta antes e após a presença de cerâmica no sítio Forte Marechal Luz. R. Museu Arq. Etn., 24: 137-151, 2014.
\end{abstract}

Resumo: Nesse estudo foram realizadas análises de isótopos de carbono e nitrogênio de esmalte dentário e dentina de indivíduos sepultados em camadas sem e com cerâmica do sítio Forte Marechal Luz, localizado no litoral de Santa Catarina. Os resultados do colágeno da dentina sugerem que os indivíduos teriam uma dieta proteica rica em recursos marinhos durante o período de formação dos dentes analisados. No entanto, comparando períodos anteriores com posteriores à presença da cerâmica, observa-se uma leve tendência para resultados mais negativos no carbono nas camadas com cerâmica, indicando um maior consumo de recursos como plantas $\mathrm{C} 3$ e animais terrestres durante os períodos posteriores de ocupação do sítio e, consequentemente uma evidência de maior diversificação alimentar.

Palavras-chave: Bioarqueologia; análises isotópicas; sambaqui; cerâmica.

\section{Introdução}

- $\begin{gathered}\text { studos isotópicos tornaram-se peça } \\ \text { fundamental em uma enorme gama }\end{gathered}$ de áreas da ciência, como hidrologia, cosmoquímica, paleoclimatologia, geocronologia, geologia econômica, oceanografia, microbiolo-

(*) Setor de Antropologia Biológica, Departamento de Antropologia, Museu Nacional, UFRJ.<muriloquintans@gmail. com>, <lessa.mn@gmail.com>,<claudia@mn.ufrj.br>.

$\left.{ }^{(* *}\right)$ Department of Anthropology, University of South Florida. <rtykot@usf.edu>. gia, agronomia e ecologia (Criss, 1999, Allègre, 2008). Na Bioarqueologia, as primeiras análises isotópicas foram datações radiocarbônicas de ossos feitas por volta da metade do século XX (Taylor 1992).

No começo da década de 1980, isótopos de carbono $\left(\delta^{13} \mathrm{C}\right)$ e nitrogênio $\left(\delta^{15} \mathrm{~N}\right)$ passaram a ser usados em estudos de dieta e economia de po-

$\left.{ }^{* * *}\right)$ Departamento de Geoquímica e Recursos Minerais, Instituto de Geociências, Universidade de Brasilia. <robertoventurasantos@gmail.com>. 
pulações humanas pretéritas. Tais estudos foram fundamentais, por exemplo, para o entendimento da transição da caça e coleta para a agricultura (introdução do cultivo do milho) em civilizações pré-colombianas da América Central e do Norte (Ambrose 1993). Desde então, a arqueometria vem discutindo padrões alimentares de populações nas mais diversas regiões do mundo.

Nos últimos anos, estes isótopos forneceram informações preciosas sobre parâmetros da alimentação de povos pré-históricos das Ilhas Canárias (Arnay-de-la-Rosa et al. 2010), de populações medievais dinamarquesas (Yoder 2010), de sítios concheiros de populações de caçadorescoletores da Coréia do Sul (Choy e Richards 2010), de povos da Idade do Bronze da Rússia (Katzenberg et al. 2009), de grupos em transição para a Idade do Bronze na península de Oman (Gregoricka 2013), entre outros.

No Brasil, estudos sobre isótopos de carbono e nitrogênio ainda são raros. Um dos primeiros trabalhos sobre o tema foi realizado por DeMasi (2001), quando foram comparados os resultados entre uma série proveniente de um sambaqui da Ilha de Santa Catarina (SC) e outra formada por oito indivíduos sepultados em distintos sítios localizados no interior do mesmo estado, incluindo da região do planalto da Serra Geral. Os resultados deste estudo demonstraram o potencial informativo dessas análises ao indicar diferenças na dieta entre as duas séries, com os sambaquieiros apresentando valores de $\delta^{13} \mathrm{C}$ e $\delta^{15} \mathrm{~N}$ compatíveis com uma alimentação baseada principalmente nos recursos marinhos, e os indivíduos do interior com uma dieta proteica rica em fauna terrestre e/ou plantas C3 e C4. Dois estudos posteriores com séries litorâneas sambaquieiras (Klökler 2008; Colonese et al. 2014) obtiveram resultados semelhantes, com os recursos marinhos se destacando na dieta desses grupos.

Isótopos estáveis de carbono $\left(\delta^{13} \mathrm{C}\right)$ e nitrogênio $\left(\delta^{15} \mathrm{~N}\right)$

A reconstrução da dieta a partir de isótopos parte do princípio de que a composição isotópica de carbono e nitrogênio no corpo está diretamente relacionada aos alimentos ingeridos (Ambrose 1993). A partir das análises de isótopos estáveis de carbono, é possivel distinguir plantas que apresentam o caminho fotossintético C3 (ex: trigo, arroz, mandioca e inhames) de plantas com caminho fotossintético $\mathrm{C} 4$ (ex: milho e milheto). Enquanto as plantas $\mathrm{C} 3$ apresentam valores de $\delta^{13} \mathrm{C}$ bem negativos, entre $-34 \%$ o e $-23 \%$, os valores de plantas C4 ficam entre $-17 \%$ a $-9 \%$ o. Estes diferentes valores de $\delta^{13} \mathrm{C}$ encontrados nas plantas são passados a seus consumidores e, ao analisar os isótopos de carbono destes consumidores, é possivel determinar se estes se alimentavam de plantas C3, C4, ou até mesmo uma mistura de ambas (Smith e Epstein 1971; Ambrose 1993).

Análises de $\delta^{13} \mathrm{C}$ também podem diferenciar dietas terrestres de dietas marinhas. Esta distinção é possível por conta da diferença de $7 \%$ ontre o $\delta^{13} \mathrm{C}$ encontrado no $\mathrm{CO} 2$ atmosférico e aquele encontrado no bicarbonato presente na água do mar, que são as fontes de carbono para a fotossíntese em ambientes terrestres e ambientes marinhos, respectivamente (Smith e Epstein 1971). Por consequência, a biota marinha apresenta valores de $\delta^{13} \mathrm{C}$ menos negativos do que as plantas $\mathrm{C} 3$. Análises de $\delta^{13} \mathrm{C}$ não são capazes, no entanto, de distinguir uma dieta marinha de uma dieta terrestre baseada em plantas $\mathrm{C} 4$, visto que há uma sobreposição nos valores isotópicos de carbono dessas duas fontes de alimento (Schoeninger e DeNiro 1984; Schwarcz 1991).

Isótopos de nitrogênio podem ser usados para avaliar o nível trófico da alimentação de um determinado indivíduo, de modo que torna possível distinguir uma dieta mais voltada para vegetais ou animais. $\mathrm{O}$ nitrogênio presente no ar atmosférico apresenta um $\delta^{15} \mathrm{~N}$ igual a $0 \%$, e este sofre enriquecimento de $3 \%$ a $4 \%$ a cada nível da teia trófica (Schoeninger et al. 1983). Dessa forma, herbívoros apresentam um $\delta^{15} \mathrm{~N}$ um pouco maior que o da planta ingerida, $\mathrm{e}$ carnívoros um $\delta^{15} \mathrm{~N}$ maior ainda. Em ambientes marinhos, o $\delta^{15} \mathrm{~N}$ chega a valores bem mais elevados que aqueles encontrados na biota terrestre, isso ocorre porque em ambientes marinhos há um maior número de níveis tróficos, além de existir uma diferença em torno de $4 \%$ entre 
o $\delta^{15} \mathrm{~N}$ de plantas terrestres e marinhas (Ambrose 1993). De modo geral, humanos que se alimentam de recursos terrestres, como plantas, apresentam valores de isótopos de nitrogênio até a casa dos $10 \%$, enquanto indivíduos que consomem uma grande quantidade de recursos marinhos podem apresentar resultados bem superiores, chegando, em alguns casos, a valores acima de 20\%o (Schoeninger e Deniro 1984).

\section{Problemática}

A ocupação do litoral de Santa Catarina, no sul do Brasil, ocorreu por volta de 6000 anos A.P. e seus primeiros habitantes seriam grupos de pescadores-coletores construtores de montes de conchas, os quais chegavam a ter até 30 metros de altura e algumas centenas de metros de comprimento, conhecidos no Brasil como sambaquis (Prous 1992; DeBlasis et al. 1998). Os construtores de sambaquis, no entanto, não estavam sozinhos no litoral meridional, tendo como vizinhos outros grupos de pescadorescaçadores-coletores desde pelo menos o quarto milênio antes da era cristã, como indicado pela datação obtida no nível mais profundo do sítio Pântano do Sul, de 4515 \pm 100 AP (Rohr 1977; Schmitz e Bitencourt 1996). Esses grupos ocuparam os chamados sítios rasos, caracterizados principalmente pela pequena espessura do pacote arqueológico e quantidade de conchas significativamente menor do que o observado nos sambaquis.

As datações radiocarbônicas disponíveis para os sítios litorâneos indicam que por volta do primeiro milênio da era cristã o sistema sambaquieiro já estava em declínio (Gaspar 1996; Lima 1999/2000). Concomitantemente à desarticulação desse sistema, a ocupação do litoral é marcada pelo aparecimento de sítios rasos com presença de cerâmica, os quais, em alguns casos, estão assentados no topo de sambaquis, como é o caso do Forte Marechal Luz. Essa cerâmica, associada à Tradição Itararé, era originalmente produzida por grupos ceramistas da região do Planalto da Serra Geral de Santa Catarina, o qual dista em torno de $100 \mathrm{~km}$ do litoral.

A relação entre os construtores de sam- baquis e os pescadores-caçadores-coletores que ocuparam os sítios rasos com cerâmica tem sido tema de discussão há anos, mas até o momento permanece como uma lacuna na arqueologia do Brasil meridional. A presença desta inovação tecnológica é um tema de extrema relevância para o entendimento dos processos de ocupação do litoral, incluindo questões sobre migração e contatos intergrupais, as quais vêm sendo amplamente discutidas na arqueologia brasileira sob distintas perspectivas e metodologias (por ex. Beck 1972; Chmyz 1976; Rohr 1977; Neves 1988; Bryan 1993; Bandeira 2004; Lessa 2005; Okumura 2007; Wesolowski 2007; Hubbe et al. 2009; Bastos et al. 2011).

As principais discussões giram em torno da possível ocupação dos sítios rasos por grupos horticultores ceramistas oriundos do Planalto. Neste sentido, estudos comparativos voltados para a dieta de grupos não ceramistas e ceramistas começam a delinear algumas diretrizes a partir da definição de diferenças no aporte proteico, na importância dos vegetais enquanto fonte energética, e na possibilidade ou não da prática da horticultura. Com o presente estudo pretende-se contribuir com as discussões mencionadas a partir do estudo da dieta através dos isótopos estáveis de carbono e nitrogênio presente na apatita do esmalte dentário e na dentina de indivíduos sepultados no sítio Forte Marechal Luz, associados aos períodos pré-cerâmico e cerâmico.

\section{O sítio Forte Marechal Luz}

O sítio Forte Marechal Luz está localizado na Ilha de São Francisco do Sul, ao norte do estado Santa Catarina (coordenadas geográficas

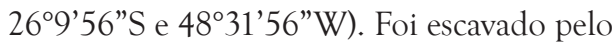
arqueólogo Alan L. Bryan em 1960, sendo que uma grande parte do depósito já havia sido removida para o uso em pavimentação de estradas. Os dados arqueológicos apresentados a seguir foram compilados de Bryan (1977, 1993).

$O$ assentamento, que se encontra próximo à baía de Babitonga e a uma praia arenosa, forneceu uma série de ocupações sem presença de cerâmica e, em períodos mais recentes, ocupações com presença de cerâmica associada a 
grupos do planalto de Santa Catarina. No total, as ocupações se estenderam por quase quatro milênios, apresentando somente alguns momentos de abandono.

O sítio está assentado em uma área privilegiada com relação à disponibilidade de recursos alimentícios, uma vez que se localiza em um ecótono litorâneo com presença de diversas zonas ecológicas, dentre elas a floresta úmida que margeia o oceano ao leste, o mangue próximo às praias protegidas a oeste, a planície arenosa, e, naturalmente, a própria baía da Babitonga, a qual provavelmente forneceu diversos recursos marinhos aos antigos habitantes desse local. Com relação à matéria prima, fontes de diabásio localizadas próximas ao local do sítio possibilitaram a fabricação de vários instrumentos líticos.

A área da escavação foi de $70 \mathrm{~m}^{2}$ e chegou a uma profundidade máxima de $6,5 \mathrm{~m}$ (com média de $3 \mathrm{~m}$ ). Foram revelados 23 estratos deposicionais maiores, separados por Bryan em sete zonas ocupacionais. Estas zonas ocupacionais representariam momentos de ocupação distintos no tempo, mantendo entre si semelhanças, mas também apresentando pequenas diferenças culturais, principalmente no repertório artefatual, nas técnicas de fabricação e no modo de sepultamento. Esta divisão por zonas ocupacionais não foi interpretada como um sinal de reocupação do sítio por grupos diferentes.

A estratigrafia do sítio é muito complexa, com muitas camadas lenticulares finas dentro dos estratos mais espessos. Em geral, as valvas de berbigão (Anomalocardia brasiliana), e os ossos de peixe predominam na composição da matriz de todos os estratos. Aparecem, também, espécimes como Ostrea sp., Mytilidae (mexilhões), além de lentes de espinhos de ouriço do mar. Os estratos mais recentes, referentes às zonas de ocupação V, VI e VII, possuem um sedimento orgânico escuro, o que, segundo Bryan, seria um sinal de intensificação da ocupação.

Não foram encontrados sepultamentos nas três zonas de ocupação mais antigas do sítio (I, II e III). A datação por ${ }^{14} \mathrm{C}$ mais antiga foi de $4290 \pm 130$ anos AP (2340 AC), sendo este considerado o período inicial da ocupação no
Forte Marechal Luz. Os sepultamentos mais antigos do sítio aparecem na zona de ocupação IV, cuja camada 6B foi perturbada por 36 sepultamentos, sete deles coletivos, mas não contemporâneos. Os mais antigos foram possivelmente sepultados pelos habitantes da camada 6 , os quais depositaram uma lente de cascas de coquinhos carbonizados datados de $1110 \pm 100$ anos AP (860 AD). Os habitantes da zona de ocupação V (camada 5) continuaram a sepultar os mortos nos depósitos anteriores, a julgar pela datação de $850 \pm 100 \mathrm{AP}(1110 \mathrm{AD})$.

Na zona de ocupação VI, carvões retirados de uma fogueira cerimonial sobre o sepultamento $n^{\circ} 5$, associado às primeiras cerâmicas do sítio, forneceram uma datação de $880 \pm 100$ AP (1070 AD). A camada 1 da última zona de ocupação (VII), a qual apresentou aproximadamente 10.000 cacos de cerâmica associada à Tradição Itararé, forneceu duas datações quase idênticas, $620 \pm 10 \mathrm{AP}(1320 \mathrm{AD})$ e $640 \pm 100$ AP (1360 AD).

Dos 65 sepultamentos humanos registrados, 42 estavam depositados em estratos sem presença de cerâmica, nas zonas IV e V (estratos 6, 5 e 6B), e 23 em estratos com presença cerâmica (1 a 4 e 4B), nas zonas VI e VII. Análises zooarqueológicas indicam que ocorreram pequenas variações nos restos faunísticos ao longo da ocupação, o que inclui a diminuição da quantidade de conchas e o aumento da quantidade de ossos de peixes e mamíferos nas ocupações mais recentes (zonas V, VI e VII). A variedade de espécies de peixes também aumentou nas zonas VI e VII, assim como a frequência de condrictes (tubarões e arraias).

\section{Material e métodos}

Os remanescentes esqueléticos do sítio Forte Marechal Luz encontram-se sob a guarda do Laboratório de Antropologia Biológica do Museu Nacional/UFRJ, no Rio de Janeiro.

A coleta dos dentes foi feita em 2007 para o desenvolvimento da dissertação de mestrado do primeiro autor, quando foram realizadas análises de isótopos de estrôncio nos esmaltes dentários. Na ocasião foram selecionados todos 
os indivíduos com dentes em condições de preservação adequadas para as análises químicas, totalizando 32 indivíduos subadultos e adultos de ambos os sexos (Bastos et al. 2011). Dos dentes selecionados previamente, 22 encontravam-se disponíveis para a atual pesquisa, os outros 10 foram disponibilizados para análises de DNA. Em função do pequeno tamanho da amostra não foram feitas comparações dos valores de isótopos entre os sexos, uma vez que resultariam em discussões inconsistentes.

Foram analisados apenas dentes permanentes, com intuito de evitar influência do leite materno nos resultados isotópicos de nitrogênio. Convém ressaltar que, uma vez que os dentes não sofrem remodelação ao longo da vida, os elementos presentes nos tecidos dentários são aqueles assimilados durante a sua formação, ou seja, durante a infância até o início da vida adulta, variando de acordo com o dente analisado (Hillson 1996). A tabela 1 apresenta informações referentes ao número do sepultamento, nível e pacote arqueológico e dente utilizado na análise.

A preparação das amostras iniciou-se com a limpeza das superfícies dos dentes com escova, sonda exploradora e/ou bisturi. Após esta etapa as amostras ficaram 20 minutos em ultrassom com água Nanopure. As coroas dentais foram submersas em ácido acético $0.5 \mathrm{M}$ por 1 hora para retirada de carbonatos contaminantes que poderiam interferir nos valores de $\delta^{13} \mathrm{C}$ da apatita biogênica.

As análises de $\delta^{13} \mathrm{C}$ foram realizadas em um Kiel IV Carbonate acoplado a um espectrômetro de massa MAT 253 da Thermo Scientific no laboratório de Geocronologia da Universidade de Brasília. Para análise, $1 \mathrm{mg}$ de cada amostra de esmalte dentário retirado de faces vestibular, lingual e/ou interdental foi colocada no auto-sampler do Kiel IV Carbonate. Os valores de $\delta^{13} \mathrm{C}$ são apresentados em PDB, tendo-se utilizado padrões NBS18 e NBS19 para verificação da acurácia e reprodutibilidade das determinações.

Para as análises de $\delta^{13} \mathrm{C}$ e $\delta^{15} \mathrm{~N}$ de colágeno cortou-se entre 0.2 a $0.3 \mathrm{~g}$ de raiz de cada dente. As amostras foram imersas em $\mathrm{NaOH}$ $0.1 \mathrm{M}$ por 24 horas para neutralização de ácidos húmicos e após enxágue foram imersas em $\mathrm{HCl} 0.25 \mathrm{M}$ por 72 horas para desmineralização. Após mais uma etapa de $\mathrm{NaOH}$ $0.1 \mathrm{M}$ por 24 horas, foi realizada a separação dos resíduos de lipídeos em uma solução de clorofórmio, metanol e água na proporção de 2:1:0.8. Os pseudomorfos de colágeno foram então enxaguados e em seguida secos em estufa a $60^{\circ} \mathrm{C}$. Foram pesadas duas alíquotas de $1 \mathrm{mg}$ de cada amostra em cadinhos de estanho para leitura em um espectrômetro de massas MAT Delta Plus da Thermo Finnigan conectado a um CHN analyzer na University of South Florida. A razão C:N e a porcentagem de colágeno de cada amostra foi obtida para verificar o grau de preservação da fração orgânica presente na dentina. Os $\delta^{13} \mathrm{C}$ e $\delta^{15} \mathrm{~N}$ foram calibrados a partir dos padrões NIST 8573 e NIST 85745 e gerados em PDB e ar atmosférico.

\section{Resultados e Discussão}

Os valores de $\delta^{15} \mathrm{~N}$ do colágeno da dentina nas camadas sem cerâmica ficaram entre $14,8 \%$ e e $16,9 \%$ o, com média $15,49 \%$ o e, na camada com cerâmica ficaram entre $14,7 \%$ o e 16,7\%o, com média de 15,86\%o. Os valores de $\delta^{13} \mathrm{C}$ do colágeno da dentina dos indivíduos das camadas sem cerâmica ficaram entre $-14,6 \%$ o $-11 \%$ o, com média de $-12,14 \%$ o. Os sepultados na camada com cerâmica tiveram valores entre $-15,5 \%$ e e $-12,1 \%$ o, com média de $-13,4 \%$ o. Por fim, os valores de $\delta^{13} \mathrm{C}$ da apatita do esmalte dos indivíduos sepultados na camada sem cerâmica ficaram entre $-9,91 \%$ o e $-5,63 \%$ o, com média $-7,95 \%$ o, já os sepultados na camada com cerâmica apresentaram valores entre $-10,72 \%$ o e $-7,57 \%$ o, com média $-9,91 \%$ o. O desvio padrão das amostras de colágeno ficou em $0.2 \%$. Em todas as amostras o colágeno da dentina apresentou boa preservação, com razão carbono/ nitrogênio entre 3.2 a 3.5 , e porcentagem de colágeno da massa total da amostra entre 5.7\% a $10.4 \%$ (tabela 1$)$.

Os valores pouco negativos de $\delta^{13} \mathrm{C}$ e altos valores de $\delta^{15} \mathrm{~N}$ (fig. 1), praticamente iguais para ambas as séries, sugerem que os recursos marinhos seriam a principal fonte proteica dos indivíduos pré-ceramistas e ceramistas sepulta- 


\begin{tabular}{llllllll}
\hline Indivíduo & Camada/Zona & Dente & $\delta^{13} \mathrm{C} \mathrm{Ap}$ & $\delta^{13} \mathrm{C}$ Col & $\delta^{15} \mathrm{~N}$ Col & C:N & \% Col \\
F2 & VII / Cerâmico & M1 S D & $-10,13 \pm 1$ & & & & \\
F5 & VI / Cerâmico & M3 S E & $-8,57 \pm 1$ & $-13,5$ & 16,7 & 3,3 & 9,9 \\
F6 & ? / Não-cerâmico & M2 I D & $-7,07 \pm 1$ & $-14,6$ & 14,8 & 3,2 & 8,4 \\
F11 & 6B / Não-cerâmico & M1 I D & $-7,52 \pm 1$ & $-11,6$ & 16,9 & 3,3 & 8 \\
F11B & 6B / Não-cerâmico & M3 I E & $-6,90 \pm 2$ & $-12,2$ & 15 & 3,5 & 8,6 \\
F18 & VII / Cerâmico & M1 I D & $-8,98 \pm 2$ & & & & \\
F19 & VII / Cerâmico & M2 & $-10,63 \pm 1$ & $-15,5$ & 14,7 & 3,5 & 9,9 \\
F20 & ?/ Não-cerâmico & M2 S E & $-8,80 \pm 1$ & & & & \\
F23 & 6B / Não-cerâmico & M2 I D & $-7,72 \pm 1$ & $-12,0$ & 15,4 & 3,4 & 5,7 \\
F26 & ?/ Cerâmico & M2 S E & $-8,05 \pm 3$ & $-12,5$ & 14,9 & 3,2 & \\
F27 & VII / Cerâmico & M2 I E & $-10,72 \pm 3$ & & & & \\
F32 & 6B / Não-cerâmico & I1 S D & & -11 & 15 & 3,5 & 8 \\
F35 & ?/ Não-cerâmico & M2 I D & $-6,44 \pm 1$ & & & & \\
F36 & 6B / Não-cerâmico & M3 I E & $-5,63 \pm 1$ & $-11,4$ & 15,4 & 3,4 & 5,9 \\
F37 & 6B / Não-cerâmico & M2 S D & $-9,65 \pm 1$ & & & & \\
F38 & 6B / Não-cerâmico & M2 S D & $-8,29 \pm 3$ & & & & \\
F39 & 6B / Não-cerâmico & M2 S E & $-9,36 \pm 2$ & & & & \\
F43 & 6B / Não-cerâmico & M2 S D & $-6,48 \pm 4$ & $-11,2$ & 15,9 & 3,4 & 3,1 \\
F48 & ?/ Não-cerâmico & M1 I D & $-9,52 \pm 2$ & & & & \\
F50 & ?/ Não-cerâmico & M2 S E & $-9,91 \pm 3$ & & & & \\
F55 & VII / Cerâmico & M3 S E & $-8,31 \pm 1$ & $-12,1$ & 16,6 & 3,4 & 10,4 \\
F56 & VII / Cerâmico & M2 S D & $-7,57 \pm 1$ & $-13,4$ & 16,4 & 3,4 & 7,2 \\
\hline & & & & & & \\
\hline
\end{tabular}

Tabela 1: Dados e resultados isotópicos das amostras analisadas do Forte Marechal Luz

dos no Forte Marechal Luz. Provavelmente o consumo maior seria de pescados, uma vez que se esses indivíduos estivessem comendo moluscos em maior quantidade, os valores de $\delta^{15} \mathrm{~N}$ tenderiam a ser mais baixos.

Esses resultados são semelhantes aos observados por DeMasi (2001) para os sambaquis Porto do Rio Vermelho I e II e Canto da Lagoa I e por Klökler (2008) para o sambaqui Jabuticabeira II, fortalecendo as premissas estabelecidas a partir da década de 90 , as quais tiveram como base estudos zooarqueológicos. Análises de restos faunísticos e a incorporação de cálculos de quantidade de carne disponível a partir de ossos e conchas demonstraram que o pescado era a principal fonte proteica dos grupos litorâneos, os quais, no entanto, estavam adaptados à exploração de outros recursos, como bivalves e gastrópodes (Lima 1991; Bandeira 1992; Figuti 1993). A antiga premissa de que grupos sambaquieiros dependiam primariamente da exploração de moluscos foi definitivamente rejeitada a partir das estimativas sobre retorno energético do consumo deste recurso, as quais demonstraram que sua coleta constitui uma atividade que gera pouco retorno em termos de quantidade 
de carne disponível para o consumo (Figuti e Klökler 1996; Klökler 2001).

Nenhum dos valores de colágeno do Forte Marechal Luz foi compativel com os valores obtidos nos indivíduos sepultados em sítios do interior de Santa Catarina, também estudados por DeMasi (2001), os quais apresentam um $\delta^{15} \mathrm{~N}$ em torno de $9 \%$, sugerindo uma dieta proteica rica em recursos terrestres, possivelmente plantas (fig. 1).

Ainda sobre os valores de $\delta^{13} \mathrm{C}$ da dentina, observa-se uma variação entre os dois períodos, embora o Teste $t$ tenha demonstrado que a diferença não é significativa $(\mathrm{p}=0,112)$. Neste ponto vale lembrar que em muitos estudos bioarqueológicos a importância dos testes estatísticos para validar a significância dos dados deve ser relativizada devido a sua pouca sensibilidade para valores baixos e representados por pequenas variações (Mendonça de Souza et al. 2003).

Essa variação no $\delta^{13} \mathrm{C}$ da dentina aponta para valores mais negativos entre os indivíduos da camada com cerâmica, o que pode ser um indicativo de maior consumo de fauna terrestre na dieta proteica, em relação ao período sem cerâmica. Os dados faunísticos do Forte Marechal Luz sustentam esta hipótese uma vez que foram achados restos de fauna terrestre em maior quantidade nas camadas com cerâmica, quando comparados com as camadas anteriores (Bryan 1993). Convém ressaltar, no entanto, que estes animais não seriam a principal fonte de proteína dos indivíduos analisados.

Animais herbívoros como o porco do mato, paca, veado e anta, todos encontrados na fauna associada ao sítio, apresentam baixos valores de $\delta^{15} \mathrm{~N}$ e, caso estes animais fizessem parte significativa da dieta proteica, os valores de $\delta^{15} \mathrm{~N}$ dos humanos tenderiam a ser menores do que os encontrados. Apenas dois indivíduos, F6 (sem cerâmica) e F19 (com cerâmica), estariam consumindo proteína com $\delta^{13} \mathrm{C}$ mais negativo em quantidade significativa, estando o primeiro bastante deslocado em relação aos demais

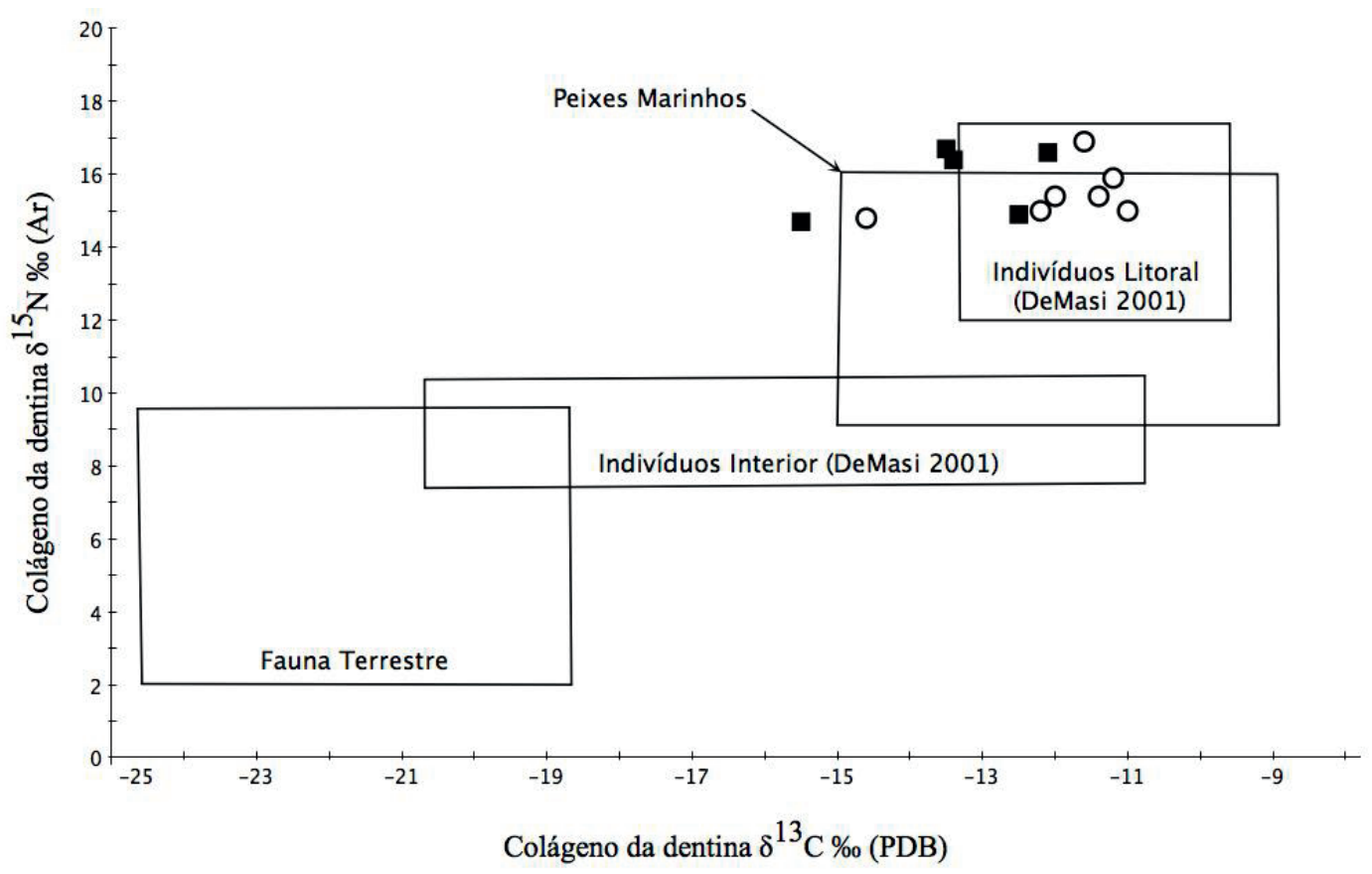

Fig. 1: Distribuição dos valores de $\delta^{13} \mathrm{Ce} \delta^{15} \mathrm{~N}$ do colágeno da dentina dos indivíduos sepultados no Forte Marechal Luz (círculo - níveis arqueológicos sem presença de cerâmica; quadrado - níveis arqueológicos com presença de cerâmica). Também são apresentados os limites dos valores obtidos para esqueletos de sítios litorâneos e do interior estudados por DeMasi (2001, 2009), e das amostras de peixes marinhos e fauna terrestre, arqueológica e atual, da região sul e sudeste do Brasil (DeMasi 2001; Bastos 2014; Colonese et al. 2014). 
indivíduos das camadas sem cerâmica. Vale lembrar, no entanto, que o sítio apresenta uma estratigrafia extremamente complexa e poucas datações, existindo, portanto, a possibilidade de interpretação equivocada quanto à camada de origem dos sepultamentos associados ao período pré-cerâmico.

Mais uma vez os resultados aqui apresentados seguem uma tendência já discutida a partir de estudos zooarqueológicos e arqueológicos, a qual sinaliza alterações no padrão de subsistência quando comparados os sambaquis e os sítios rasos mais recentes, com presença de cerâmica. Os dados indicam que a dieta dos grupos litorâneos teria passado de uma exploração intensa dos frutos do mar em geral, principalmente peixes, e fauna terrestre pouco representada (Lima 1991; Bandeira 1992; Figuti 1993; Figuti e Klökler 1996), para uma maior diversificação alimentar que inclui, além dos recursos marinhos, a caça de um grande número de mamíferos terrestres e aquáticos, o que se reflete na proliferação das pontas ósseas (Beck 1972; Tiburtius et al. 1950/51; Silva et al. 1990; Bandeira 1992; Schmitz et al. 1993; Schmitz 1996). Algumas hipóteses têm sido aventadas para a mudança no padrão de subsistência dessas populações, como a de uma diminuição na oferta de alimentos marinhos em função das oscilações do nível do mar (Hurt 1974; Tenório 1995), ou ainda o esgotamento das colônias de moluscos provocado por um sistema altamente predatório e imprevidente de coleta (Lima 1999/2000).

É importante ressaltar que os dados isotópicos do colágeno da dentina estão relacionados somente com a proteína consumida durante a vida do indivíduo e, desta forma, alimentos pobres em proteínas, como muitos vegetais, passam despercebidos nos resultados obtidos. Porém, diferentemente do colágeno, o carbono presente na apatita do esmalte é formado por toda a dieta do indivíduo (carboidratos, proteínas e lipídeos) e pode ser considerado um bom indicador de dieta total (Krueger e Sullivan 1984; Ambrose 1993).

Plantas C3 geralmente apresentam valores de $\delta^{13} \mathrm{C}$ entre -34\% a - $23 \%$ o, com média de $-26 \%$ o. Já em plantas C4, os valores encontram- se geralmente entre $-17 \%$ a $-9 \%$ o, com média de -13\%o (Smith e Epstein 1971). É importante mencionar que o carbono ingerido na dieta sofre fracionamento isotópico ao ser assimilado nos ossos e dentes, de modo que os valores de $\delta^{13} \mathrm{C}$ da hidroxiapatita tornam-se entre $9 \%$ o e $14 \%$ mais positivos que o $\delta^{13} \mathrm{C}$ da dieta e os valores de $\delta^{13} \mathrm{C}$ do colágeno em torno de $5 \%$ mais positivos (Lee-Thorp et al. 1989; Cerling e Harris 1999; Tykot et al. 2009).

Uma pesquisa de dieta controlada por Jim e colaboradores (2004) comparou valores de isótopos de carbono da apatita de três roedores que receberam $100 \%$ de dieta proteica de origem marinha, entretanto, cada um recebeu uma dieta não proteica (carboidrato) distinta. Enquanto um roedor recebeu $100 \%$ de carboidrato de plantas C3, outro recebeu 100\% de carboidrato de plantas $\mathrm{C} 4$, e um último recebeu $50 \%$ de carboidratos $\mathrm{C} 3$ e $50 \%$ de carboidratos $\mathrm{C} 4$. Os valores de $\delta^{13} \mathrm{C}$ da apatita foram de $-13,44 \%$ o, $-3,54 \%$ o e $-8,64 \%$ o, respectivamente (fig. 2). A figura 2 mostra a comparação entre os valores de $\delta^{13} \mathrm{C}$ da apatita nas duas séries do Forte Marechal Luz e os valores obtidos por Jim e colabotradores (2004). É importante mencionar que humanos e roedores apresentam algumas diferenças fisiológicas, e que estas diferenças podem gerar níveis de fracionamento isotópico distintos durante a incorporação do carbono na apatita (Krueger e Sullivan 1984; Jim, Ambrose e Evershed 2004). Portanto, não é possível determinar o grau de acurácia na comparação entre os valores de $\delta^{13} \mathrm{C}$ das séries aqui estudadas e dos roedores, devendo a mesma ser interpretada como uma tendência.

Apesar da ressalva acima mencionada, os valores observados de $\delta^{13} \mathrm{C}$ da apatita sugerem que, embora a principal fonte de proteína do grupo como um todo tenha sido os recursos marinhos, uma parte da dieta total, associada ao aporte energético, poderia ser composta também por alimentos com $\delta^{13} \mathrm{C}$ mais negativos, como plantas $\mathrm{C} 3$, principalmente entre os indivíduos do período cerâmico (fig. 3).

Novamente, a comparação dos valores de $\delta^{13} \mathrm{C}$ da apatita entre os indivíduos sepultados nas camadas sem cerâmica e com cerâmica 


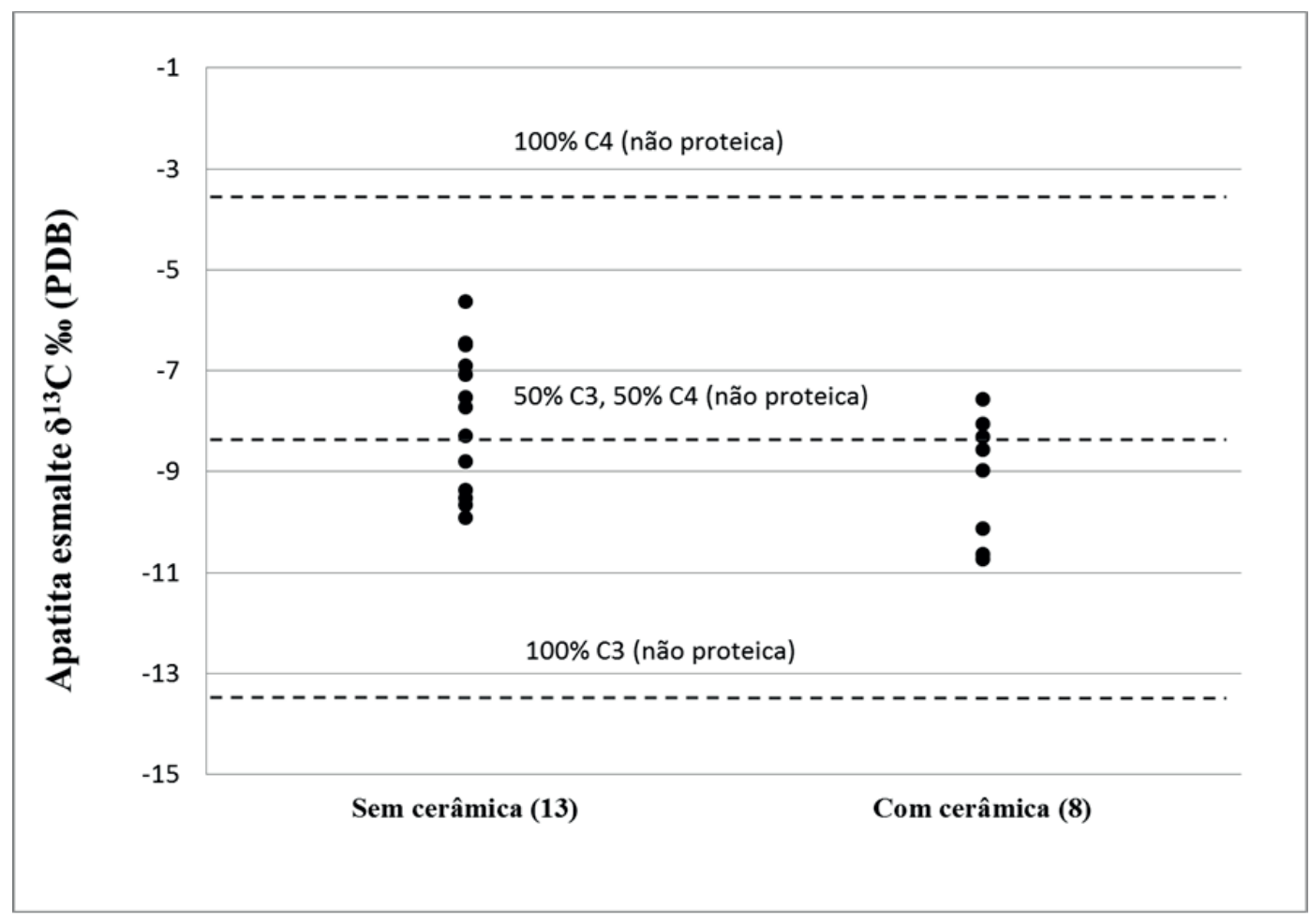

Fig. 2: $\delta^{13} \mathrm{C}$ da apatita do esmalte dos indivíduos sepultados em camadas sem cerâmica e com cerâmica do sítio Forte Marechal Luz. As linhas tracejadas representam os valores de $\delta^{13} \mathrm{C}$ dos roedores com dieta não proteica $100 \%$ C4, 100\% C3 e 50\% C3 e 50\% C4 (Jim Ambrose e Evershed, 2004).

sinaliza haver uma diferença visível, mas não significativa pelo Teste-t $(p=0,067)$. Partindo-se do pressuposto discutido anteriormente sobre a validade dos testes estatísticos, entende-se aqui que esta diferença pode ser um indicativo de alteração no padrão alimentar após o aparecimento da cerâmica, com maior consumo de recursos C3.

A importância dos vegetais na dieta de populações litorâneas já foi discutida por Wesolowski (2007), quando foram analisados fitólitos e grãos de amido em cálculos dentários de indivíduos da camada sem cerâmica do Forte Marechal Luz e de outros sambaquis do litoral norte de Santa Catarina. No Forte Marechal Luz foram identificados grânulos de amido de plantas C3, como batata doce (Ipomoea batatas) e Araceae, e foram observadas formas variadas de fitólitos não identificadas, indicando um consumo generalizado de alimentos amiláceos. Ambos os trabalhos, portanto, sugerem que o consumo de plantas C3 desempenhou, no mínimo, um papel suplementar na obtenção de energia (carboidratos) dos indivíduos sepultados no Forte Marechal Luz.

Da mesma forma, Scheel-Ybert e colaboradores (2003) através de análises antracológicas em sambaquis do litoral sul e sudeste, sustentam que há presença de coquinhos, sementes e fragmentos de tubérculos em praticamente todos os níveis arqueológicos analisados. Ainda segundo os autores, sua conservação sugere que eram largamente utilizados pelos sambaquieiros e que as plantas, de um modo geral, contribuíram mais para a alimentação desses grupos do que é usualmente admitido.

Infelizmente, o presente trabalho não pode contribuir para as discussões sobre a questão do manejo e consumo do milho (Zea mays) por esses grupos litorâneos, uma vez que se trata de uma planta $\mathrm{C} 4$, apresentando valor de $\delta^{13} \mathrm{C}$ similar aos valores encontrados em recursos marinhos (Ambrose 1993; Tykot et al. 2009). 


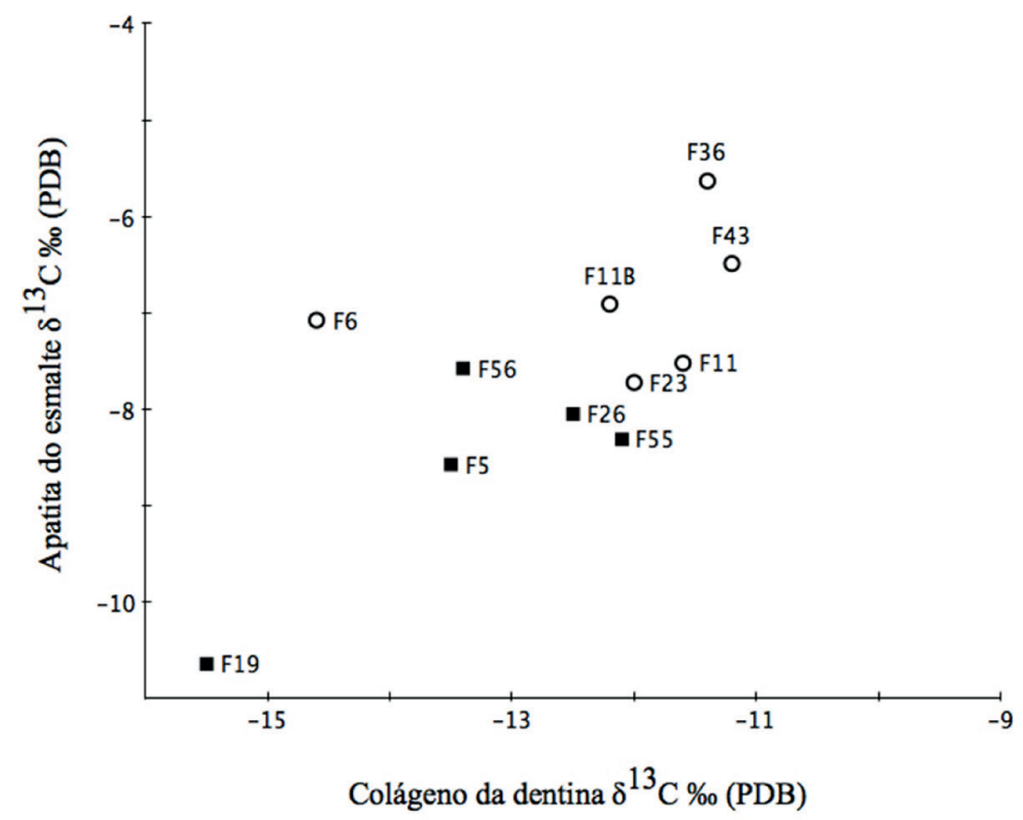

Fig. 3: Valores de $\delta^{13} \mathrm{C}$ do colágeno da dentina e da apatita do esmalte dos indivíduos sepultados nas camadas sem cerâmica (círculo) e com cerâmica (quadrado) do sítio Forte Marechal Luz.

Desta forma, análises isotópicas de carbono não têm como avaliar se este recurso teria alguma relevância na dieta energética de grupos pescadores-coletores, os quais estariam ingerindo recursos marinhos em grande quantidade.

\section{Considerações finais}

Os estudos de isótopos de carbono e nitrogênio ainda são raros em séries arqueológicas brasileiras, a despeito de todo o potencial informativo que representam. A necessidade e acessibilidade a equipamentos específicos e técnicos especializados para tratamento das amostras, operação dos equipamentos e leitura dos resultados, torna a pesquisa cara, lenta e de difícil execução.

Por outro lado, a necessidade de preservação adequada dos dentes e presença de quantidade suficiente de esmalte, o qual apresenta padrões de desgaste expressivos em populações litorâneas, são fatores que influenciam na representatividade das séries disponíveis para análise.
Esta, sem dúvida, foi uma dificuldade observada no presente trabalho. $\mathrm{O}$ pequeno tamanho das séries examinadas confere ao trabalho um caráter preliminar, mas ainda assim foi possível observar tendências que complementam os dados arqueológicos e bioarqueológicos já produzidos sobre dieta, e tornam mais consistentes as discussões sobre a questão do aparecimento da cerâmica no litoral.

Os dados aqui apresentados apontaram para pequenas alterações na dieta entre os indivíduos sepultados nas camadas com cerâmica, tanto do ponto de vista do aporte proteico, com um aumento de consumo de recursos terrestres, quanto do aporte energético, com um aumento discreto de consumo de plantas C3. É possível inferir, portanto, que a dieta tornou-se mais diversificada, com menor dependência exclusiva dos recursos marinhos, especialmente o pescado. Embora possivelmente o maior consumo de vegetais esteja representando um manejo mais sistemático desses recursos, a presença da cerâmica 
não pôde ser associada a qualquer forma de horticultura propriamente dita.

Estudos com outras séries litorâneas, principalmente de sítios rasos com presença de cerâmica, permitirão um enriquecimento das discussões aqui apresentadas, principalmente quanto à tendência de diversificação da dieta. Se essa diversificação ocorreu de forma homogênea ou não entre os vários grupos deste período é uma questão relevante, sobre a qual já estamos nos debruçando em um trabalho em fase final de preparação com a série do sítio Praia da Tapera, localizado no litoral central de Santa Catarina.

Finalmente, reforçamos a importância das análises de isótopos estáveis de carbono e nitrogênio, principalmente da apatita do esmalte, para a arqueologia e bioarqueologia de grupos litorâneos. A utilização desses dados para inferências sobre consumo de vegetais, vestígio dificilmente preservado no registro arqueológico, constitui-se uma eficiente e bem vinda ferramenta para o entendimento do modo de vida desses grupos.

\section{Agradecimentos}

Gostaríamos de agradecer a Luís Henrique Mancini e Eduardo Carvalho por toda assistência durante a leitura de amostras no Laboratório de Estudos Geocronológicos, Geodinâmicos e Ambientais da Universidade de Brasília. Agradecemos ao professor Eduardo Neves da Universidade de São Paulo e professores Gabriela Nardoto, Lucieth Vieira e Koji Kawashita da Universidade de Brasília, pelas sugestões sobre a interpretação dos dados. Por fim, agradecemos a Capes pela bolsa de doutorado e doutorado sanduíche fornecida ao primeiro autor, o qual desenvolveu o presente estudo durante seu doutoramento pelo Programa de Pós-graduação em Geologia da Universidade de Brasília.

BASTOS, M.Q.R.; LESSA, A.; RODRIGUES-CARVALHO, C.; TYKOT, R.H.; SANTOS, R.V. Carbon and nitrogen isotope analysis: diet before and after the arrival of ceramic at Forte Marechal Luz Site. R. Museu Arq. Etn., 24: 137-151, 2014.

\begin{abstract}
This study focused on carbon and nitrogen stable isotope analysis of dentin and enamel of individuals buried in pre-ceramic and ceramic layers of the Forte Marechal Luz site, located in the coast of Santa Catarina State, southern Brazil. The dentin collagen values indicate that the individuals had a protein diet based mainly on marine resources during the formation period of the analyzed teeth. However, there is a slight difference in the carbon results between the individuals related to the pre-ceramic and the ceramic periods, suggesting that the latter inhabitants were consuming a little bit more resources like C3 plants and terrestrial fauna than before, and therefore indicating that there was a greater diversification in the diet after the arrival of the ceramic in the region.
\end{abstract}

Keywords: Bioarchaeology; isotopic analysis, shell mounds, pottery. 


\section{Referências bibliográficas}

Allègre, C.J. 2008. Isotope Geology. Cambridge: Cambridge University Press.

Ambrose, S.H. 1993. Isotopic analysis of paleodiets: methodological and interpretive considerations. In: Sandford, M.K. (Ed.). Investigations of Ancient Human Tissue. Langhome: Gordon and Breach. 59-130 pp.

Arnay-de-la-rosa, M.; González-Reimers, E.; Yanes, Y.; Velasco-Vázquez, J.; Romanek, C.S.; Noakes, J.E. 2010. Paleodietary analysis of the prehistoric population of the Canary Islands inferred from stable isotopes (carbon, nitrogen and hydrogen) in bone collagen. Journal of Archaeological Science, 37: 1490-1501.

Bandeira, D.R. 1992. Mudança na estratégia de subsistência do sítio arqueológico Enseada I Um estudo de caso. Dissertação de Mestrado. Universidade Federal de Santa Catarina, Florianópolis.

Bandeira, D.R. 2004. Ceramistas pré-coloniais da Baía da Babitonga SC, Arqueologia e etnicidade. Tese de Doutorado. Campinas: UNICAMP.

Bastos, M. Q. R. 2014, Dos Sambaquis do sul do Brasil à diáspora africana: Estudos de geoquímica isotópica de séries esqueléticas humanas escavadas de sítios arqueológicos brasileiros. Tese de doutorado. Brasília: UNB.

Bastos, M.Q.R.; Mendonça de Souza, S.F.; Santos, R.V.; Lima, B.A.F.; Santos, R.V.; Rodrigues-Carvalho, C. 2011, Human mobility on the Brazilian coast: analisys of strontium isotopes in archaeological human remains from the sambaqui of Forte Marechal Luz. Anais da Academia Brasileira de Ciências 83(2): 731-743.

Beck, A.M. 1972. A variação do conteúdo cultural dos sambaquis: litoral de Santa Catarina. Tese de doutorado. São Paulo: Faculdade de Filosofia Letras e Ciências Humanas, USP.

Bryan, A.L. 1977. Resumo da arqueologia do sambaqui de Forte Marechal Luz. Arquivos do Museu de História Natural 2: 9-30.

Bryan, A.L. 1993. The Sambaqui at Forte Marechal Luz, State of Santa Catarina, Brazil. Corvallis: Center for the Study of the First Americans, Oregon State University.

Cerling, T.E.; Harris, J.M. 1999. Carbon isotope fractionation between diet and bioapatite in ungulate mammals and implications for ecological and paleoecological studies. Oecologia 120: 347-363.

Chmyz, I. 1976. A ocupação do litoral dos Estados do Paraná e Santa Catarina por povos ceramistas. Revista de Estudos Brasileiros 1: 7-43.

Choy, K.; Richards M.P. 2010. Isotopic evidence of diet in the Middle Chulmun period: a case study from the Tongsamdong shell midden, Korea. Archaeological Antrhopological Science 2: 1-10.

Colonese, A.C.; Collins, M.; Lucquin, A.; Eustace, M.; Hancock, Y.; Ponzoni, R.A.R.; Mora, A.; Smith, C.; DeBlasis, P.; Figuti, L.; Wesolowski, V.; Plens, C.R.; Eggers, S.; Farias, D.S.E.; Gledhill, A.; Craig, O.E. 2014. Long-Term Resilience of Late Holocene Coastal Subsistence System in Southeastern South America. Plos One 9: e93854.

Criss, R.E. 1999. Principles of Stable Isotope Distribution. New York: Oxford University Press.

DeBlasis, P.; Fish, S.K.; Gaspar, M.D.; Fish, P. 1998, Some references for the discussion of complexity among the sambaqui moundbuilders from the southern shores of Brazil. Revista de Arqueologia Americana 15: 75-105. 
DeMasi, M.A.N. 2001. Evolução da Dieta das Populações Pré-históricas da Costa Sul do Brasil, Santa Catarina. In: XI Congresso da Sociedade de Arqueologia Brasileira, Rio de Janeiro. Anais. XI Congrresso Sociedade de Arqueologia Brasileira 1-136.

Figuti, L. 1993. O homem pré-histórico, o molusco e o sambaqui: considerações sobre a subsistência dos povos sambaquieiros. Revista do Museu de Arqueologia e Etnologia 3: 67-80.

Figuti, L.; Klökler, D.M. 1996. Resultados preliminares dos vestígios zooarqueológicos do Sambaqui Espinheiros II (Joinville, SC). Revista do Museu de Arqueologia e Etnologia 6: 169-187.

Gaspar, M.D. 1996. Análise das datações radiocarbônicas dos sítios de pescadores, coletores e caçadores. Boletim do Museu Paranaense Emílio Goeldi (série Ciências da Terra) 8: 81-91.

Gregoricka, L.A. 2013. Geographic origins and dietary transitions during the bronze age in the Oman peninsula. American Journal of Physical Anthropology 152(3): 353-369.

Hillson, S. 1996. Dental Anthropology. Cambridge: Cambridge University Press.

Hubbe, M.; Neves, W.A.; Oliveira, E.C.; Strauss A. 2009. Postmarital residence practice in southern Brazilian coastal groups: Continuity and Change. Latin American Antiquity 20(2): 267-278.

Hurt, W.R. 1974. The interrelationships between the natural environment and four sambaquis, coast of Santa Catarina, Brazil. Occasional Papers and Monographs $\mathrm{n}^{\circ} 1$. Bloomington: Indiana University Museum.

Jim, S.; Ambrose, S.; Evershed, R.P. 2004. Stable carbon isotopic evidence for differences in the dietary origin of bone cholesterol, collagen, and apatite: implications for their use in paleodietary reconstruction. Geochimica et Cosmochimica Acta 68: 61-72.
Katzenberg, M.A.; Goriunova, O.; Weber, A. 2009. Paleodiet reconstruction of Bronze Age Siberians from the mortuary site of Khuzhir-Nuge XIV, Lake Baikal. Journal of Archaeological Science 36: 663-674.

Klökler, D. 2001. Construindo ou deixando um sambaqui? Análise de sedimentos. Região de Laguna-SC. Dissertação de Mestrado. Universidade de São Paulo, São Paulo.

Klökler, D. 2008. Food for Body and Soul: Mortuary Ritual in Shell Mounds (Laguna, Brazil). Tese de doutorado. Tucson: University of Arizona.

Krueger, H.W.; Sullivan, C.H. 1984. Models for carbon isotope fractionation between diet and bone. In Turnlund J.E., Johnson P.E (Eds.) Stable isotopes in Nutrition. Washington DC: American Chemical Society. 205-222.

Lee-Thorp, J.A.; Sealy, J.C.; Van Der Merwe, N.J. 1989. Stable carbon isotope ratio differences between bone collagen and bone apatite, and their relationship to diet. Journal of Archaeological Science 16: 585-99.

Lessa, A. 2005. Reflexões preliminares sobre paleoepidemiologia da violência em grupos ceramistas litorâneos: (I) Sítio Praia da Tapera - SC. Revista do Museu de Arqueologia e Etnologia 15: 199-207.

Lima, T.A. 1991. Dos mariscos aos peixes: um estudo zooarqueológico de mudança de subsistência na pré-história do Rio de Janeiro. Tese de Doutorado. São Paulo: USP.

Lima, T.A. 1999/2000. Em busca dos frutos do Mar: Os pescadores-coletores do litoral centro-sul do Brasil. Revista USP 44: 270-327.

Mendonça de Souza, S.; Carvalho, D.M.; Lessa, A. 2003 Paleoepidemiology: Is there a case to answer? Memórias do Instituto Oswaldo Cruz 98: $21-27$

Neves, W.A. 1988. Paleogenética dos grupos pré-históricos do litoral sul do Brasil 
(Paraná e Santa Catarina). Pesquisas (série Antropologia) 43.

Okumura, M.M.M. 2007. Diversidade morfológica craniana, micro-evolução e ocupação pré-histórica da costa brasileira. Tese de Doutorado. São Paulo: Instituto de Biociências, USP.

Prous, A. 1992. Arqueologia Brasileira. Brasília: Editora UnB.

Rohr, J. A. 1977. O sítio Arqueológico do Pântano do Sul SC - F - 10. Florianópolis: Governo do Estado de Santa Catarina.

Scheel-Ybert, R.; Eggers, S.; Wesolowski, V.; Petronilho, C.C.; Boyadjian, C.H.; DeBlasis, P. 2003. Novas perspectivas na reconstituição do modo de vida dos sambaquieiros: uma abordagem multidisciplinar. Revista de Arqueologia 16: 109-37.

Schmitz, P.I. 1996. Escavações arqueológicas do Pe. João Alfredo Rohr, S.J. - Visão de conjunto dos sítios da Tapera, Armação do Sul, Laranjeiras I e II, Pântano do Sul e Cabeçudas. Pesquisas (Série Antropologia) 53: 183-190.

Schmitz, P.I.; Verardi, I.; De Masi, M.A.; Rogge, J.H.; Jacobus, A.L. 1993. Escavações arqueológicas do Pe. João Alfredo Rohr, S.J. - O sítio da Praia de Laranjeiras II. Uma aldeia da Tradição ceramista Itararé. Pesquisas (Série Antropologia) 49.

Schmitz, P.I.; Bitencourt, A.L.V. 1996. O sítio arqueológico do Pântano do Sul. Pesquisas (Série Antropologia) 53: 77-124.

Schroeninger, M.J.; Deniro, M.J.; Tauber, H. 1983. Stable nitrogen isotope ratios reflect marine and terrestrial components of prehistoric human diet. Science 220: 1381-383.

Schoeninger, M.J.; Deniro, M.J. 1984. Nitrogen and carbon isotope composition of bone collagen from marine and terrestrial animals. Geochimica et Cosmochimica Acta 48: 625-639.

Schwarcz, H.P. 1991. Some theoretical aspects of isotope paleodiet studies. Journal of Archaeological Science 18: 261-275.

Silva, S.B.; Schmitz, P.J.; Rogge, J.H.; De Masi, M.A.; Jacobus, A.L. 1990. Escavações arqueológicas do Pe. João Alfredo Rohr, S.J. - O sítio arqueológico da Praia da Tapera: um assentamento Itararé e Tupiguarani. Pesquisas (Série Antropologia) 45.

Smith B.N., Epstein S. 1971. Two categories of $13 \mathrm{C} / 12 \mathrm{C}$ ratios for higher plants. Plant Physiology 47:380-384.

Taylor, R.E. 1992. Radiocarbon dating of bone: to collagen and beyond. In: Taylor, R.E., Long, A., Kra, R.S. (Eds.), Radiocarbon Dating After Four Decades. Berlin: Springer. 375-402 pp.

Tenório, M.C. 1995. Estabilidade dos grupos litorâneos pré-históricos: uma questão para ser discutida. In: Beltrão, M. (Ed.) Arqueologia do Estado do Rio de Janeiro. Niterói: Arquivo Público do Estado do Rio de Janeiro. 43-50 pp.

Tiburtius, G.; Bigarella, I.K.; Bigarella, J.J. 1950/51. Nota prévia sobre a jazida paleoetnográfica de Itacoara (Joinvile, Estado de Santa Catarina). Arquivos de Biologia e Tecnologia V/VI: 315-366.

Tykot, R.H.; Falabella, F.; Planella, M.T.; Aspillaga, E.; Sanhueza, L.; Becker, C. 2009. Stable isotopes and archaeology in central Chile: methodological insights and interpretative problems for dietary reconstruction. International Journal of Osteoarchaeology 19: 156-170.

Wesolowski, V. 2007. Cáries, desgaste, cálculos dentários e micro-resíduos da dieta entre grupos pré-históricos do litoral norte de Santa Catarina: 
Murilo Q. R. Bastos

Andrea Lessa

Claudia Rodrigues-Carvalho

Robert H. Tykot

Roberto V. Santos

É possível comer amido e não ter cárie? Tese de doutorado. Rio de Janeiro: Escola Nacional de Saúde Pública, FIOCRUZ.
Yoder, C. 2010. Diet in medieval Denmark: a regional and temporal comparison. Journal of Archaeological Science 37: 2224-36 